\title{
TRABALHO E EDUCAÇÃO NO CONTEXTO DAS POLÍTICAS NEOLIBERAIS: PRAZER E DOR NO COTIDIANO DA ESCOLA
}

Labor and education in neoliberal political contexts:pleasure and pain in school daily life

Trabajo y educación en contextos políticos neoliberales: placer y dolor en el cotidiano escolar

\section{Maria de Lourdes Alves**1, Carlos Cardoso Silva ${ }^{2}$}

${ }^{1}$ Docente do Curso de Pedagogia, Universidade Estadual de Goiás - UEG, Anápolis, Goiás, Brasil.

${ }^{2}$ Docente do Curso de Pedagogia, Universidade Federal de Goiás - UFG, Goiânia, Goiás, Brasil.

*Correspondência: Rua RC Qd. 06 - Lt. 08 S/No - residencial Canadá, Goiânia, Goiás, Brasil. CEP:74.370-624.

E-mail: lurdinhaalves@terra.com.br

Artigo recebido em 12/06/2017 aprovado em 04/08/2017 publicado em 08/08/2017.

\section{RESUMO}

O objetivo deste texto é suscitar reflexões e análises que podem ser estabelecidas, entre educação e trabalho frente ao modelo neoliberal, desvelando o cotidiano da escola, por meio de pesquisas bibliográficas que discutem essa temática. Os trabalhos pesquisados apontam para: controle, regulação, proletarização docente, desvalorização do trabalho do professor, elementos que não raro têm como consequência o adoecimento docente. Mas a pesquisa bibliográfica, revela um movimento de resistência de professores que não aceitam a mera condição de executores e resistem de modo silencioso a este padrão que pretende moldar o humano. Trata-se de uma revisão bibliográfica de cunho qualitativo, acerca do tema em análise, no campo da educação e das políticas educacionais.

Palavras-chave: Trabalho docente. Políticas neoliberais. Adoecimento

\begin{abstract}
This essay's main goal is to promote reflections and analysis that may be established between education and labor, considering both of them in the neoliberal context. It aims to cover the school daily routine through bibliographical research that discusses these themes. The theoretical references studied indicate control, regulation, teacher proletarianization and teaching devaluation are the most common elements in teachers' lives, which frequently cause them various diseases. Nevertheless, the bibliographical research shows a resistance movement by teachers who do not accept these conditions and suffer silently because of these patterns. It is, then, a bibliographical and qualitative revision about education and labor, inserting itself on the education and educational politics research field.
\end{abstract}

Keywords: Teaching labor. Neoliberal politics. Diseases.

\section{RESUMEN}

Ese texto busca promover reflexiones y análisis acerca de la relación entre educación y trabajo en el contexto neoliberal. Pretende mostrar el cotidiano de la escuela por medio de investigaciones bibliográficas acerca de los dos temas. Las obras teóricas consultadas demuestran que el control, la regulación, la proletarización y desvalorización de los profesores son los elementos más comunes en la vida de aquellos que siguen la carrera en educación y les causa enfermedades variadas. A pesar de eso, la investigación indica un movimiento de resistencia por parte de los profesores que no aceptan esas condiciones y sufren silenciosamente a causa de los padrones que intentan moldar el hombre. El artículo es, entonces, una revisión bibliográfica de carácter qualitativo acerca de la 
educación y del trabajo, insertandose en el campo de investigación de la educación y de las políticas educacionales.

Palabras-clave: Trabajo docente. Políticas neoliberales. Enfermedades.

\section{INTRODUÇÃO}

O ponto de partida deste texto é a reflexão sobre a relação entre educação e trabalho; para tal, faz-se necessário apontar a concepção de educação e trabalho que orienta esta análise. O vínculo entre educação e trabalho é inerente ao desenvolvimento do ser humano.

A análise que Mézaros (2008, p. 09) faz da educação aponta desafios importantes, tais como, "a educação não deve qualificar para o mercado, mas para a vida, [...] educação não é uma mercadoria". Mézaros, na obra citada, nos incita a refletir sobre os descaminhos da educação na sociedade contemporânea capitalista, e aponta possibilidades de superação da lógica desumanizadora do capital, mostra que "[...] educar é colocar fim à separação entre Homo faber e Homo sapiens". "É resgatar o sentido estruturante da educação e de sua relação com o trabalho, as suas possibilidades criativas e emancipatórias". (GRAMSCI, apud MÉZAROS, 2008, p.16)

A perspectiva de educação defendida por Mézaros (2008), é o contraponto que nos permite fugir à lógica desumanizante que produz o sofrimento no cotidiano da escola. Este texto tem como objetivo discutir a sobrecarga no professor das atividades docentes, associada ainda à degradação das condições de trabalho no campo biopsicossocial.

\section{EDUCAÇÃO E TRABALHO: SIGNIFICADO E CONCEPÇÕES}

Na perspectiva de Mézaros (2008, p.16.) “[...] educar não é mera transferência de conhecimento mas sim conscientização e testemunho de vida. É construir, libertar o ser humano das cadeias do determinismo neoliberal." O capitalismo transforma tudo em mercadoria, a educação é uma mercadoria e a escola ela mesma muitas vezes se assemelha a um shopping. O grande problema desta relação é que não é uma relação simples de compra e venda, como se faz com uma mercadoria qualquer, pois o professor não é um mero vendedor e o aluno não pode comprar conhecimento ele deve ser capaz de construir o conhecimento, via esforço próprio, mas que na condição de cliente, na maioria das vezes, ele não está disposto a fazer, porque na lógica desumanizante do capital o aluno não quer o conhecimento, ele deseja apenas um certificado, a comprovação de cada etapa concluída, mas no meio deste caminho está o professor, que não deseja apenas certificar o estudante, ele deseja a transformação, a emancipação, de um novo homem no processo educacional.

Nesta relação conflituosa, a educação pode ser vislumbrada tanto como instrumento de emancipação como de alienação, de acordo com maior ou menor submissão da educação à lógica neoliberal. O professor pode ser apenas um executor de tarefas, ou se insubordinar ao trabalho prescrito e fazer de fato o que deve ser feito, do modo como deve ser feito, e não apenas o que está prescrito.

$\mathrm{O}$ ato de ensinar, tem como pressuposto o prazer no trabalho bem feito, bem realizado, a dor, o desânimo deriva da submissão à lógica gerencial, que na maioria das vezes ignora o humano, o trabalho criativo, vivo e enxerga apenas a meta a ser cumprida. Este modelo fica evidente a seguir:

Porém como se pode depreender, nesse domínio não é suficiente conhecer: a racionalidade 
gestionária não apenas colhe informações, mas busca modelar aquilo sobre o qual incide. (ALVES, 2016, p. 101)

A racionalidade gestionária, é um modelo de gestão recorrente, onde a regulação e o controle, pretendem moldar a escola, o professor e o aluno, às expectativas do mercado, Vantin, (2008), apud, Alves, (2016, p. 101) aponta para uma racionalidade própria da fábrica, transposta para a escola, “[...] espírito de engenheiro, o que corresponde a um modo de construção do conhecimento marcado pela preocupação com a medida, com a formalização e o cálculo, mas também voltado à ação." Mas que na maioria das vezes não considera o sujeito, o ator da ação.

Nesta proposta fica latente a ideia de implantar na escola o ideário produtivo da fábrica, no qual, é recorrente a fixação de metas, eficiência, eficácia, controle, regulação. Neste cenário a avaliação não tem por objetivo diagnosticar, avaliar significa controlar, racionalizar, verificar a relação custolbenefício, o professor é um "operário em uma linha de produção" e o aluno um produto, cenário no qual a lógica da criatividade, do pensar vê-se subsumida ao ideário produtivista neoliberal.

Entre as consequências da implantação do ideário neoliberal na organização escolar e na atividade docente de modo geral está a proletarização docente, exposta por Najjar (1992), Nunes (1998) e Therrien (1998), apud Tumolo e Fontana, (2008, p. 162). Os autores salientam que "o professor vem sofrendo um processo de proletarização que o assemelha ao trabalhador fabril". As reformas neoliberais incidem sobre o trabalho docente de modo a desqualificar, desprestigiar o professor, mas os estudos afirmam que mesmo neste processo de proletarização, onde as condições de trabalho são precárias, o professor deve ser analisado de forma diferenciada, pois a especificidade de trabalho docente que o distingue do proletário é a autonomia, que é ameaçada, mas que persiste. Há um movimento dialético, no qual o professor é desconstruído e se reconstrói, ao mesmo tempo avança e retrocede, num processo continuo de resistência.

$$
\text { É interessante observar que as políticas }
$$
neoliberais avançam sobre o modelo de organização da escola e do trabalho escolar, sob a orientação das agências internacionais, mas em contraponto a este avanço, há pelo menos duas formas de resistência que podem ser identificadas: a quantidade expressiva de pesquisas sobre educação e trabalho, e os resultados destas pesquisas que em síntese apresenta uma resistência do professor em relação ao controle, ao ranqueamento, à proletarização; poderíamos arriscar que o professor é um rebelde silencioso, no interior da sala, neste espaço, o professor faz o que deve ser feito, o oficio, a arte de fazer torna-se mais importante na atividade do que o formulário a ser preenchido. Ao realizar uma análise das "Diretrizes do pacto pela educação em Goiás”, Libâneo (2011), corrobora a perspectiva da pesquisa como força questionadora e motora das mudanças no âmbito da educação.

Em linhas gerais, Libâneo (2011, p. 2) indica algumas orientações prescritas pelos organismos internacionais (Banco Mundial, UNESCO, OMC) para as escolas e os resultados esperados:

-Fixação centralizada de objetivos, metas e competências do sistema de ensino, dentro de uma política de resultados;

-Introdução de métodos de avaliação para o sistema escolar por meio de testes estandardizados (medição da aprendizagem a partir de parâmetros);

- Ensino de tipo tecnicista, instrumental, em que se mede a qualidade da aprendizagem com base na porcentagem atingida pelo aluno em conhecimentos determinados pelo sistema de ensino;

- Obtenção de resultados por meio de provimentos de insumos (textos didáticos apostilados, avaliação externa por testes, formas de capacitação de professores com custo baixo, gerenciamento, parcerias com empresas 
privadas, prêmios e bônus às escolas e professores bem sucedidos), sem atender a aspectos qualitativos;

- Descentralização do sistema visando a autonomia das escolas e responsabilização dos professores pelos resultados, medida pela avaliação externa de desempenho e incentivo ao desempenho individual;

- Comparação de resultados entre escolas, professores e alunos, promovendo competição entre eles;

- Implantação de modelos empresariais de gerenciamento (metas quantificadas, valorização da meritocracia, incentivo ao desempenho individual, tutoria coaching, monitoramento).

São orientações balizadas por uma política neoliberal, que objetiva instaurar uma lógica extremamente competitiva, que compara: alunos, professores, escolas; promovendo um ranqueamento, com prêmio e punições, com consequências drásticas. Segundo Libâneo, (2011) ocorre a instrumentalização crescente da educação, com vistas a educar para o mercado; entrada da educação em um universo economicista; aumento considerável do individualismo dos atores; privilegio da competição em detrimento da cooperação; institucionaliza-se "o professor-executor", visão que desconsidera a dimensão humana do ato de educar.

Libâneo (2011), apresenta uma severa crítica ao modelo neoliberal, que tem como foco a quantidade em detrimento da qualidade. Trata-se de uma política que responsabiliza, controla, domina, em última instância é excludente. Estabelece uma competição acirrada, onde o fracasso ou sucesso é atribuído ao indivíduo. Nesta perspectiva, professores e alunos são vistos como objeto, numa visão economicista; a escola deixa de ser uma instituição educativa por excelência e passa a ser tratada como uma empresa prestadora de serviço.

É notório que é necessário questionar a lógica neoliberal gerencial, pois a escola não é em si uma instituição prestadora de serviços educacionais, ela é um território do saber, espaço de formação de seres humanos, na qual ocorre uma relação dialógica, e a aprendizagem é processo e não produto final numa linha de produção.

A lógica gerencial, instrumental, na educação ignora as peculiaridades do ato de ensinar: ensinoaprendizagem constitui-se numa ação dialógica, não é uma rua de mão única, não é um jogo de um só, é necessário que se estabeleça uma relação de cumplicidade entre professor e aluno para que o processo de ensino-aprendizagem se desenvolva, para que se possa alcançar o resultado desejado: a construção de um saber significativo para quem ensina e para quem aprende, e não apenas "bom desempenho do aluno nos testes".

Faz-se necessário questionar: é apenas o econômico que o sistema educativo deve ter como fim? Um professor-executor, que gera um alunoexecutor, de testes e tarefas? Esta forma de pensar e gerir o processo educativo limita sobremaneira o ato de educar, deixando de lado ocupações essenciais, como ação criadora, a formação do sujeito crítico, pensante, que sonha, que deseja ver o mundo para além dos "muros" do capital, ou seja, um sujeito autônomo para viver em grupo e em sociedade.

\section{POLÍticas NEOLIBERAIS E SEUS REFLEXOS NO TRABALHO DOCENTE}

As consequências deste modelo capitalista neoliberal no cotidiano da escola são inevitáveis, o professor é o alvo preferencial destas políticas que pretendem reduzir custos e aumentar o índice de aprendizagem dos alunos; é uma conta difícil de se fazer, reduzir custos e aumentar a eficiência. Neste contexto as políticas incidem sobre o trabalho docente, muitas vezes produzindo um grande desconforto para o professor. Alves (2016), apresenta 
pesquisas nas quais fica evidente o engessamento do trabalho do professor, a padronização imposta ao ato de ensinar, ações que geram um grande mal-estar para os docentes, pois a ação de ensinar, na perspectiva gerencial, é guiada pela avaliação/controle, que produz ranqueamento, prêmios e punições, transformando a escola em uma arena, na qual a competição é a palavra de ordem.

A avaliação não é apenas um diagnóstico. Ela induz o que se deve aprender, como aprender, é um instrumento que permite classificar alunos, professores e escolas, assim a avaliação tende a fragilizar aquele que está sendo avaliado. Há um sentimento de medo; são recorrentes as perguntas: “será que eles vão gostar?" "É assim mesmo que eu devo fazer? Há um misto de sentimentos contraditórios, um desejo de se adequar, para ser aceito, bem avaliado, bem classificado. Mas, por outro lado, o saber que carregamos, acumulado ao longo de nossa jornada na educação, nos incita a educar para emancipar, para romper com a opressão, que significa a avaliação em larga escala e o ranqueamento ao qual professores e alunos são lançados.

O sistema de avaliação atual tende a desconsiderar o contexto, a diversidade, em que os processos educacionais se dão. De acordo com Assis e Amaral, (2013), Verifica-se uma tensão entre o que se deseja ensinar, como ensinar e o que se deve ensinar, com vistas a atender aos testes. Há uma inversão de papéis, os testes não avaliam a aprendizagem, esta ocorre para atender ao que deverá ser cobrado nos testes de larga escala.

Deste modo a avaliação padronizada, segundo Alves (2016) induz o currículo, que se pauta nos testes, deixando de lado questões fundamentais no processo de ensino-aprendizagem, tais como: ampliar a visão de mundo dos estudantes, torná-los críticos, reflexivos, desenvolver a sensibilidade, a flexibilidade, torná-los cidadãos aptos a criar, decidir, executar, de forma segura. A carga-horária das disciplinas é pensada não para atender às necessidades educacionais dos alunos mas para atender de forma eficiente aos testes. Nesta lógica o bom aluno é aquele capaz de memorizar, repetir, reproduzir; o bom professor é aquele capaz de "moldar" os alunos para que tenham bom desempenho nos testes.

A desqualificação e a desvalorização é uma prática, na perspectiva neoliberal, que tende a valorizar as metas não alcançadas e desvalorizar as ações cotidianas exitosas. Práticas como estas tendem a gerar um adoecimento docente. Deste modo cabe indagar qual a correlação que se estabelece entre o modelo de gestão da "eficiência" e o adoecimento dos docentes, provocado muitas vezes pelas pressões deste sistema que avalia, controla e na maioria das vezes não dá a devida atenção à aprendizagem que é o que move os atores na escola.

Mas os problemas continuam e interferem na vida dos alunos e professores. A perspectiva da classificação e do ranqueamento, apresenta consequências danosas para os alunos que não se enquadram no perfil do "bom aluno". O modelo tende a aprofundar a exclusão dos alunos com maiores dificuldades e gerar até mesmo a segregação daqueles alunos com desempenho considerado insatisfatório, tendo em vista os parâmetros da avaliação em larga escala.

Outro aspecto importante ao analisar o modelo de gestão neoliberal, e que é recorrente, é a maquiagem muitas vezes impressa aos dados que procuram mascarar a realidade excluindo alunos considerados ruins nos dias dos testes, ou ainda, ajudando alunos com dificuldades na realização dos testes, produzindo deste modo, resultados que não faz jus à realidade avaliada. 
Todo o conjunto de instrumento de avaliação, gestão controle, incide sobre a vida do professor de modo deletério, proletarizando, fragilizando, provocando em certa medida o adoecimento de docentes. Barros e Louzada (2007) apresentam estudos esclarecedores sobre o tema; as autoras coordenam pesquisas que tratam da temática da saúde docente. Conforme relatam, o foco da pesquisa realizada por elas esta na maneira como os docentes organizam o trabalho na escola e o modo como o trabalho se desenvolve e a relação saúde e a doença no ato educativo.

Nesta perspectiva, não entendemos que as lutas e batalhas cotidianas produzam o adoecer, mas, pelo contrário, devem ser uma possibilidade de escapar a servidão e à impotência, criando outras possibilidades de vidaltrabalho. (BARROS e LOUZADA, 2007, p. 14)

Entretanto a relação entre trabalho e educação se revela desgastante para professores em situações extremas. A pesquisa bibliográfica realizada traz à tona depoimentos que exemplificam o desgaste do docente em relação às situações de trabalhos em que os docentes se encontram, tais situações expostas abaixo nos incitam a buscar o nexo entre o trabalho docente e o adoecimento no trabalho, Vianelo (2006), apud, Assunção e Oliveira, (2009), apresenta, um depoimento de uma professora que deixa claro a sobrecarga de trabalho e a exaustão à qual a professora é exposta:

Os alunos querem que você explique individualmente, saem do lugar, não aceitam que você explique como uma turma. Por causa dos porquês, tem que pegar na mão [...]. Acho que a atenção individualizada controla a disciplina [...]. É uma correria, as turmas são diferentes, não têm um desempenho semelhante, alguns mais fracos e isso tudo demanda uma variedade de ações. Tem dia que esqueço até o que fiz.
As salas lotadas e com alunos com dificuldades educacionais heterogêneas exigem do professor para além do que este é capaz de oferecer, gerando assim uma sobrecarga de trabalho, pois no ato cotidiano da ação o professor se sente incapaz de atender a todas as demandas, mas por outro lado ele deseja fazer o melhor, há então um hiato, o desejo de fazer que se confronta com a impossibilidade humana de realizar; situações assim geram sentimento de fracasso, insucesso, incapacidade de resolver, que de algum modo pode acarretar o adoecimento docente.

Assunção e Oliveira, (2009), apontam que além do trabalho na escola os professores lidam ainda com os pais que contraditoriamente valorizam mais a educação dos filhos, mas por outro lado valorizam menos os professores, mas desejam que eles façam o que eles, os pais, não estão conseguindo: educar, estabelecer limites para as crianças. De acordo com o relato abaixo, Noronha (2001), apud Assunção e Oliveira, (2009, p. 357):

É difícil trabalhar com estas crianças [...] elas são difíceis e eu me sinto bem cansada [...] eu tento conversar com eles só que às vezes o aluno foge ao controle e a gente grita [...] às vezes o aluno foge tanto, mas tanto, da disciplina que a gente tem que pegar pelo braço [...] quando os pais vêm, eles falam que não têm como, se a gente quiser até bater, porque eles não têm como controlá-los em casa.

Situações como a descrita acima tendem a gerar uma forte relação entre trabalho docente e adoecimento no trabalho. Pesquisa publicada no Jornal Estadão, no dia 24 de Março de 2016, apresenta um quantitativo expressivo de professores da Rede Estadual de Ensino Paulista que entram de licença médica todos os dias (372 licenças por dia) e segundo os mesmo dados $27 \%$ destas licenças são por transtorno mental. A matéria deste Jornal lista alguns depoimentos de professores que reforçam a tese do 
adoecimento no trabalho. Apontam situações de indisciplina, desrespeito como causas principais. As consequências são doenças como; Síndrome do Pânico, depressão. São apontadas condições difíceis de trabalho na Rede que poderiam estar motivando o adoecimento docente, tais como: alta carga horária de trabalho; desilusão em relação aos resultados do trabalho: "Há um sentimento de impotência, de perseguir uma meta que nunca é alcançada", afirma Aparecida Néri de Souza, da Faculdade de Educação da Universidade Estadual de Campinas (Unicamp). Toledo e Vieira (2016).

O trabalho do professor para além do ato de ensinar, o trabalho real, vai muito além do prescrito, "o trabalho na escola é o espaço da atividade", (Schwartz, 2002) apud Barros e Louzada, (2007, p, 31). O sujeito, diante da atividade, renormaliza, faz o que deve ser feito. $\mathrm{O}$ ato de reinventar, mesmo desafiando normas, é um modo de se manter saudável diante das normas prescritas, a completa submissão adoece, petrifica o ser; o ato de reinventar é um ato de coragem, um ato de vida, no qual o ser humano imprime ao ato de fazer a sua subjetividade, o modo de fazer próprio peculiar de cada sujeito.

\section{CONSIDERAÇÕES FINAIS}

A pesquisa realizada para a elaboração deste texto nos permitiu descobrir alguns nexos da relação trabalho e educação no contexto das políticas neoliberais. As políticas educacionais das últimas décadas provocaram mudanças substanciais no ambiente escolar que incidem de modo especial sobre a gestão e organização escolar. A perspectiva que vem sendo adotada é uma perspectiva empresarial/economicista, na qual os custos devem ser reduzidos e a qualidade elevada, as metas são estabelecidas e devem ser cumpridas. Este cenário gera um "mal estar" na escola, um imenso desconforto a professores, coordenação e até mesmo aos alunos, que também devem se adequar à nova ordem escolar.

A educação escolar sob a égide neoliberal tem provocado, na perspectiva de Assunção e Oliveira (2009), a intensificação do trabalho docente. A hipersolicitação e sobrecarga no professor, associada ainda à degradação das condições de trabalho, todos estes fatores associados não trazem resultados desejados pela lógica gerencial, eficiência e eficácia; ao contrário tem provocado o adoecimento docente e comprometido a qualidade da educação escolar.

Contudo a pesquisa revela um dado interessante: a resistência docente, como um elemento que mantém a autonomia do professor em atividade, "nos processos de pensar-fazer seu trabalho", Barros e Louzada, (2007, p. 32). A pesquisa realizada pelos autores citados, apresenta o ato de realizar como se deve ao trabalho, mesmo contrariando normas e prescrições, como um elemento que permite escapar ao processo de adequação à "qualidade total". Percebe-se que ao mesmo tempo que o professor deseja atender às determinações prescritas, ele mantém sua autonomia no espaço da sala de aula, ele realiza o ato de ensinar como deve ser e não como está prescrito.

Em síntese, mesmo "encarcerado" em um sistema que controla, avalia, responsabiliza, fica evidente que a resistência é o que permite que o docente continue a exercer a sua atividade como deve ser: ensinando crianças a ler, escrever, realizar operações matemáticas, compreender o ambiente ao seu redor, mas principalmente ensinando-as a lutar por um mundo mais justo, humano e solidário.

A rebeldia consiste em não se curvar, não se deixar moldar de acordo como o modelo imposto, mas a cada dia, a cada aula, a cada gesto, sonhar e 
educar para a cidadania plena, possibilitando o devir de um mundo mais humano. Portanto, é importante ressaltar que o processo educativo difere do processo de escolarização. O que adoece o professor e o aluno é a cobrança exagerada pela escolarização como produto, resultado, mercadoria. De acordo René Hubert (1885 - 1954), a educação é o processo contínuo de desenvolvimento das faculdades físicas, intelectuais e morais do ser humano, a fim de melhor se integrar na sociedade ou no seu próprio grupo.

Todos os autores declararam não haver qualquer potencial conflito de interesses referente a este artigo.

\section{REFERÊNCIAS}

ALVES. Wanderson Ferreira. Avaliar e gerir: força e miséria de um ideário presente nas políticas educacionais contemporâneas. Revista Educação Brasileira, Rio de Janeiro, v..21, n. 64, p. 189-207, jan\mar. 2016.

AMARAL, Nelson Cardoso; ASSIS, Lucia Maria de. Avaliação da Educação por um sistema nacional. Revista Retratos da escola. Brasília, v. 7 n. 12 p. 27-48, jan.ljun. $2013 . \quad$ Disponível: http\lwww.esforce.org.br

ASSUNÇÃO, Ada Ávila; OLIVEIRA, Dalila Andrade. Intensificação do Trabalho e Saúde dos Professores. Educação e Sociedade, Campinas, vol. 30, n. 107, p.349-372, maiolago. 2009. Disponível em: http://www.cedes.unicamp.br

BARROS, Maria Elizabeth Barros de. Dor-desprazertrabalho docente: como desfazer essa tríade. Psicol. USP, São Paulo, n. 18(4) p. 13-34 outldez, 2007.
HUBERT, René, História da Pedagogia. Trad., Luiz Damasco Penna e J. B Damasco Penna. Atualidades Pedagógicas, vol. 66 Companhia Editora Nacional, 1976.

LIBÂNEO, José Carlos. Considerações críticas sobre o documento "Diretrizes do pacto pela educação: Reforma educacional Goiânia setembro, 2011.

MÉZAROS, Stván. A educação para além do capital. $2^{\mathrm{a}}$ Ed. São Paulo, Boitempo, 2008.

TUMOLO, Paulo S; FONTANA, Klamer B. Trabalho docente e capitalismo: um estudo crítico da produção acadêmica da década de 1990. Educação e Sociedade. Capinas, vol. 29, n. 102, p. 159-180, jan. labr. 2008.

VIEIRA, Victor; TOLEDO, Luiz Fernando. SP dá a professores 372 licenças por dia; $27 \%$ transtorno mental. O Estado de São Paulo, São Paulo, 24 de março de 2016. Educação. 